\title{
STEK PUCUK MASOI (Cryptocarya massoia) DENGAN PEMBERIAN BERBAGAI KONSENTRASI IBA (INDOLE BUTYRIC ACID)
}

\section{(Shoot Cutting of Masoi (Cryptocarya massoia) with The Several Treatments of Iba (Indole Butyric Acid) Concentrations)}

\author{
Wilson Miriono ${ }^{1}$, Bernadus Benni Rettob ${ }^{1}$ dan Ana Tampang ${ }^{1 *}$ \\ Jurusan Kehutanan, Fakultas Kehutanan Universitas Papua Manokwari, Papua Barat, \\ 98314. Tlp/Fax: +62986211065. \\ ${ }^{\square}$ Penulis Korespondensi: Email: ana_sylvae@yahoo.com \\ Diterima: 02 Agus 2015| Disetujui: 20 Jan 2016
}

\begin{abstract}
Abstrak
Masoi (Cryptocarya massoia) memiliki nilai ekonomi tinggi namun belum dibudidayakan secara luas. IBA (Indole Butyric Acid) sering digunakan untuk meningkatkan keberhasilan stek tanaman. Tujuan dari penelitian adalah untuk mengevaluasi beberapa konsentrasi IBA (Indole Butyric Acid) terhadap pertumbuhan stek masoi. Penelitian menggunakan empat perlakuan konsentrasi larutan IBA yaitu kontrol (tanpa IBA), IBA 75 ppm, 100 ppm, dan 125 ppm. Persentase stek hidup tertinggi (65\%) diperlihatkan oleh kontrol dan perlakuan konsentrasi larutan IBA $125 \mathrm{ppm}$. Sementara persentase stek bertunas dan stek berkalus menunjukan bahwa semua perlakuan yang diberikan tidak berbeda secara signifikan.
\end{abstract}

Kata kunci: IBA (Indole Butyric Acid), masoi, stek pucuk.

\begin{abstract}
Masoi (Cryptocarya massoia) has been potential in terms of generating economic value, but not widely well-managed yet. IBA (Indole Butyric Acid) is often used to increase level of success in plant growth.The objective of this study was to evaluate response of several IBA concentrations on the growth of shoot cutting of masoi. This study used 4 treatments of IBA concentration namely: control, IBA 75 ppm, 100 ppm, and 125 ppm, towards three replications. The result showed that control and 125 ppm of IBA had the highest cutting survival percentage (65\%), while the percentage of cutting with shoot and callus showed that all treatments given were not significantly different.
\end{abstract}

Keywords: IBA (Indole Butyric Acid), masoi, shoot cutting.

\section{PENDAHULUAN}

Masoi (Cryptocarya massoia) merupakan tanaman yang memiliki kandungan minyak pada bagian kulit sehingga dijadikan sebagai bahan obat tradisional. Hasil ekstraksi terhadap kayu Masoi mengandung senyawa aktif utama adalah massoilactone. Senyawa massoilactone diketahui banyak digunakan pada industri makanan dan kosmetik sebagai flavouring agent dan juga digunakan sebagai obat penenang (Triantoro dan Susanti, 2007). Selain itu juga kayu masoi cocok digunakan untuk bahan bangunan ringan dan tiang-tiang 
terendam air karena kayu masoi tahan terhadap serangan penggerek laut (Sikoway, 2009).

Masyarakat pada umumnya hanya mengambil bagian kulit kayu masoi untuk diperdagangkan namun cara pemanenannya dengan cara menebang pohon sehingga diduga keberadaan masoi di hutan alam semakin berkurang. Nilai ekonomi yang dimiliki masoi ditambah lagi keberadaannya di alam jumlahnya tidak banyak sementara pengambilan masoi masih mengandalkan dari hutan alam menyebabkan akan terjadi kelangkaan bahkan kepunahan jenis masoi.

Pembudidayaan masoi masih terbatas berasal dari cabutan anakan di hutan alam. Beberapa penelitian telah dilakukan oleh Sikoway (2009), Mora (2010) dan Rumakewi (2012) sebagai upaya dalam pembudidayaan masoi untuk memulai langkah awal mengenai silvikultur yang baik bagi tanaman masoi. Upaya penyediaan bibit dapat dilakukan secara generatif maupun secara vegetatif. Pembudidayaan secara vegetatif masoi perlu dilakukan untuk menyelamatkan jenis ini.

Perbanyakan tanaman secara vegetatif yang lazim dilakukan adalah dengan stek. Hal penting yang perlu diperhatikan dalam menyetek adalah perolehan stek berakar dan bertunas dalam waktu yang singkat. Salah satu cara untuk merangsang pertumbuhan akar dan tunas pada stek adalah dengan pemberian zat pengatur tumbuh tumbuhan. Abidin (1985) menyatakan bahwa zat pengatur tumbuh tanaman berperan dalam pertumbuhan dan perkembangan tanaman, salah satunya adalah auksin. Auksin berperan dalam pengembangan sel, phototropisme, geotropisme, pertumbuhan akar, partenokarpi, absisi, dan pembentukan kalus.

IBA (indole butyric acid) merupakan salah satu jenis auksin yang lazim digunakan untuk memacu perakaran dibandingkan dengan jenis auksin lainnya (Salisbury dan Ross, 1995). Kusumo (1984) menyatakan bahwa IBA memiliki sifat kimia lebih stabil dan mobilitasnya di dalam tanaman rendah sehingga pemakaiannya lebih berhasil. Pemberian zat pengatur tumbuh tumbuhan umumnya dalam konsentrasi rendah. IBA memiliki kepekatan optimum lebih fleksibel. Perlakuan pemberian IBA terhadap stek pucuk Picea abies memberikan respon perakaran terbaik dibandingkan perlakuan NAA (Yang et al. 2015) begitupula pada stek Tectona grandis terhadap respon persentase stek berakar (Husen dan Pal, 2007).

Beberapa hasil penelitian melaporkan bahwa terdapat peran IBA dalam pertumbuhan stek pada beberapa jenis tanaman. Samber (2002) melaporkan bahwa pemberian IBA dengan konsentrasi 1,5\% menghasilkan jumlah persentase stek berakar tertinggi yaitu $100 \%$ stek berakar dibandingkan konsentrasi IBA $2 \%$ dan $2.5 \%$ pada stek pucuk anakan alam jenis lawang (Cinnamomum culilawan BL). Pemberian konsentrasi 50 ppm hormon IBA pada stek pucuk sowang (Xanthostemon novaguanensis) menghasilkan jumlah akar terbanyak yaitu 24,17 akar (Masitoh, 2004). Selanjutnya dilaporkan oleh Allo (2004) bahwa pertumbuhan stek pucuk kayu cina (Decussocarpus wallichiamus (Presl) de Laub) pada perlakuan IBA dengan konsentrasi $30 \mathrm{ppm}$ memberikan respon 
persentase stek hidup yaitu $73,6 \%$ dan persentase stek berakar 42,4\%. Stek Dalbergia melanoxylon memberikan respon persentase stek berakar dan jumlah akar tertinggi pada perlakuan IBA 300 ppm (Amri et al. 2010). Hasil-hasil penelitian ini menunjukkan bahwa pertumbuhan stek membutuhkan konsentrasi optimum IBA yang berbedabeda tergantung jenis tanaman yang digunakan sehingga perlu dilakukan penelitian pemberian perlakuan beberapa konsentrasi IBA pada stek masoi (Cryptocarya massoia) sebagai upaya budidaya masoi.

\section{METODE PENELITIAN}

Penelitian dilaksanakan di Amban Manokwari selama 3 bulan yaitu tanggal 27 September 2013-02 Januari 2014. Penelitian menggunakanRancangan Acak Lengkap (RAL) yang terdiri dari 4 (empat) taraf, yaitu tanpa pemberian IBA (kontrol), larutan IBA konsentrasi 75 ppm (K1), 100 ppm (K2), dan 125 ppm (K3). Setiap perlakuan diulang sebanyak 3 kali sehingga terdapat 12 satuan percobaan dan setiap satuan percobaan digunakan 20 stek masoi

Media tanam yang digunakan adalah campuran pasir kali dan tanah. Pasir dan tanah yang digunakan dibersihkan dengan cara diayak dan disangrai untuk proses sterilisasi. Tanah dan pasir dicampur dengan perbandingan $2: 1 / 2$ dan diisi ke dalam polibag kemudian disemprotkan dengan fungisida dan dibiarkan 2 hari sebelum stek ditanam untuk mencegah jamur pada media tersebut.

Bahan stek yang digunakan yaitu diambil dari satu pohon induk masoi, dari cabang-cabang yang sehat, terletak pada sisi yang terkena sinar matahari. Bahan stek diambil dari bagian pucuk dengan ukuran diameter $\pm 0,9 \mathrm{~cm}-1,2 \mathrm{~cm}$, panjang stek $\pm 20 \mathrm{~cm}$. Bagian pangkal bahan stek dipotong miring $\left(45^{\circ}\right)$ dan dilakukan pemangkasan setengah daun. Bahan stek yang telah disiapkan direndam dalam masing-masing larutan IBA berdasarkan konsentrasi yang telah dibuat yaitu, 75 ppm, 100 ppm dan 125 ppm serta air sebagai kontrol. Setiap unit percobaan diletakkan dalam persemaian yang diberi sungkup plastik. Pemeliharaan terhadap bahan stek yang telah ditanam meliputi penyiraman dan pengukuran suhu dan kelembaban udara persemaian.

Data yang dikumpulkan yaitu respon pertumbuhan stek. Data respon pertumbuhan dianalisis menggunakan analisis ragam (ANOVA) uji $\mathrm{F}$ pada $\alpha$ 5\%. Uji Tukey dilakukan untuk melihat perbedaan antar perlakuan. Analisis data menggunakan program SPSS.

\section{HASIL DAN PEMBAHASAN}

Respon pertumbuhan stek masoi hingga akhir pengamatan selama 3 bulan terlihat bahwa stek masoi (Cryptocarya massoia) mampu untuk bertahan hidup, bertunas dan tumbuh kalus namun belum menunjukkan pertumbuhan akar stek. Rataan respon stek hidup, stek bertunas dan stek berkalus pada tiap perlakuan dapat dilihat pada Tabel 1 . 
Tabel 1. Rata-rata persentase stek hidup, persentase stek bertunas dan persentase stek berkalus.

\begin{tabular}{lccc}
\hline & \multicolumn{3}{c}{ Respon } \\
\cline { 2 - 4 } Perlakuan & $\begin{array}{c}\text { Stek } \\
\text { hidup } \\
(\%)\end{array}$ & $\begin{array}{c}\text { Stek } \\
\text { bert } \\
\text { unas } \\
(\%)\end{array}$ & $\begin{array}{c}\text { Stek } \\
\text { berkalus } \\
(\%)\end{array}$ \\
\hline K0 (Kontrol) & $65^{\mathrm{a}}$ & $57^{\mathrm{a}}$ & $57^{\mathrm{a}}$ \\
K1 (75 ppm) & $45^{\mathrm{b}}$ & $33^{\mathrm{a}}$ & $30^{\mathrm{a}}$ \\
K2 (100 ppm) & $41^{\mathrm{b}}$ & $38^{\mathrm{a}}$ & $35^{\mathrm{a}}$ \\
K3 (125 ppm) & $65^{\mathrm{a}}$ & $42^{\mathrm{a}}$ & $43^{\mathrm{a}}$ \\
\hline
\end{tabular}

Keterangan: Huruf yang sama pada nilai rataan pada kolom menandakan antar perlakuan tidak berbeda nyata pada taraf $\alpha=5 \%$.

Hasil analisis ragam pada $\alpha=5 \%$ menunjukkan bahwa terdapat perbedaan pengaruh perlakuan konsentrasi IBA terhadap persentase stek hidup masoi. Hasil Uji Tukey menunjukkan bahwa persentase stek hidup yang diberi larutan IBA 125 ppm tidak berbeda nyata dengan persentase stek hidup yang tidak diberi larutan IBA, namun berbeda nyata dengan pemberian larutan IBA 75 ppm dan $100 \mathrm{ppm}$. IBA dapat membantu pertumbuhan stek pada konsentrasi yang tepat. Pada stek Ficus hawaii, konsentrasi IBA 4000ppm memberikan persen tumbuh tertinggi yaitu 43,7\% (Siddiqui dan Husain, 2007) begitupula untuk persentase stek hidup dan panjang tunas Ficus binnendijkii (Hamed et al. 2014). Salisbury dan Ross (1995) menyatakan bahwa pengikatan auksin terjadi pada konsentrasi yang rendah dan tepat secara fisiologis. Konsentrasi auksin yang lebih tinggi dari konsentrasi optimum dapat menyebabkan kematian tanaman (Pallardy, 2008), walaupun terlihat peningkatan konsentrasi IBA dari
75 ppm ke konsentrasi 125 ppm masih menunjukkan peningkatan persentase stek hidup, stek bertunas dan stek berkalus.

Hasil analisis ragam (ANOVA) terhadap persentase stek bertunas dan berkalus terlihat bahwa perlakuan pemberian IBA pada konsentrasi 75 ppm, 100 ppm dan 125 ppm memberi pengaruh yang tidak berbeda nyata dengan tanpa pemberian IBA (Tabel 1). Amri et al. (2010) menyatakan bahwa pemberian IBA pada stek Dalbergia melanoxylon memberikan respon yang signifikan terhadap perakaran stek namun tidak signifikan terhadap persentase stek berkalus. Dalam pertumbuhan tunas, stek pucuk memiliki masa primordial tunas (masa istrahat tunas), dan masa primordial tunas ini akan pendek jika kebutuhan karbohidrat terpenuhi serta adanya pemberian zat pengatur tumbuh. Namun menurut konsep Anthony Trewavas pada tahun1980-an bahwa respon pertumbuhan, adaptasi, diferensiasi, morfogenesis dan perkembangan pada tanaman lebih banyak ditentukan oleh tingkat kepekaan sel daripada tingkat konsentrasi hormonal dalam sel (Santoso dan Nursandi, 2001). Kehadiran tunas sangat penting terhadap proses inisiasi akar karena penghasil auksin yang diperlukan untuk diferensiasi sel (Hayati et al. 2012).

Hingga akhir pengamatan, terlihat bahwa terdapat stek yang telah mampu untuk membentuk kalus walaupun belum menunjukkan adanya pertumbuhan akar pada stek. Kalus pada stek maupun kultur jaringan merupakan massa sel yang mengalami dediferensiasi yaitu proses perkembangan balik dari bagian dewasa tanaman menjadi sekelompok sel yang terus menerus membelah (Santoso dan Nursandi, 2001). Kalus secara alami 
muncul dan tumbuh pada permukaan tumbuhan yang berasal dari kambium akibat proses pelukaan. Keberhasilan stek dipengaruhi oleh faktor bahan stek, cara pengerjaan (perlakuan pada stek) dan kondisi lingkungan selama penyetekan (Adriana et al. 2014). Aplikasi auksin interaktif dengan perlakuan lainnya, jenis material dan variabel lingkungan mempengaruhi kemampuan perakaran stek (Leakey, 2004). Salisbury dan Ross (1995) menyatakan bahwa banyaknya kegagalan penggunaan auksin pada stek berkaitan dengan penggunaan stek yang berasal dari tumbuhan dewasa.

Kemampuan stek masoi untuk hidup, bertunas dan berkalus dikarenakan kondisi lingkungan persemaian selama penelitian yang mendukung pertumbuhan stek. Suhu rata-rata harian persemaian selama penelitian adalah $25^{\circ} \mathrm{C}-30^{\circ} \mathrm{C}$ sedangkan kelembaban harian yaitu 97$100 \%$ Kondisi lingkungan pada rumah tumbuh stek beberapa jenis tanaman hutan memiliki kondisi suhu $25-30^{\circ} \mathrm{C}$ dan kelembaban 85-90\% (Danu et al. 2006). Rata-rata suhu dan kelembaban udara dalam sungkup bagi pertumbuhan stek pucuk masoi cukup sesuai dengan syarat suhu dan kelembaban optimum untuk pertumbuhan stek.

\section{DAFTAR PUSTAKA}

Abidin, Z. 1985. Dasar-dasar pengetahuan tentang zat pengatur tumbuh. Angkasa, Bandung.

Adriana, Winarni WW, Prehaten D, Nawangsih G. 2014. Pertumbuhan stek cabang Bambu Petung (Dendrocalamus asper) pada media tanah, arang sekam dan kombinasinya. Jurnal Ilmu Kehutanan Vol.8 No.1.
Allo, DOT. 2004. Pengaruh Tingkat Konsentrasi Larutan IBA (Indole Butyric Acid) Stek Pucuk Kayu Cina (Decussocarpus wallichianus (Presel) de Laub ) Skripsi Sarjana Kehutanan, UNIPA,Manokwari.

Amri E, Lyaruu HVM, Nyomora AS, Kanyeka ZL. 2010. Vegetative propagation of African Blackwood (Dalbergia melanoxylon Guill. \& Perr.): effects of age of donor plant, IBA treatment and cutting position on rooting ability of stem cuttings. New Forest 39: 183-194.

Danu, Pramono AA, Siregar N. 2006. Atlas Benih Jilid VI; Perbanyakan vegetatif beberapa jenis tanaman hutan. Balai Penelitian Teknologi Perbenihan Tanaman Hutan. Bogor

Hamed B, Hossein Z, Kosar N, Mostafa NF. 2014. Effect of different concentrations of IBA and time of taking cutting on rooting, growth and survival of Ficus binnendijkii 'Amstel Queen' cuttings. Not Sci Biol 6 (2): 163-166.

Hayati E, Sabaruddin, Rahmawati. 2012. Pengaruh jumlah mata tunas dan komposisi media tanam terhadap pertumbuhan setek tanaman Jarak Pagar (Jatropha curcas L). Jurnal Agrista Vl. 16 No. 3. 129-134.

Husen A, Pal M. 2007. Metabolic changes during adventitious root primordium development in Tectona grandis Linn cuttings as affected by age of donor plants and auxin (IBA and NAA) treatment. New Forest 33: 309-323.

Kusumo, S. 1984. Zat pengatur tumbuh tanaman. CV.Yasaguna. Bogor.

Leakey, RRB. 2004. Physiology of vegetative reproduction. In: Burley, Jeffrey, Evans, Julian, and 
Youngquist, J.A, (eds.) Encyclopaedia of Forest Science. Academic Press, London, UK.

Masitoh, S. 2004. Respon pertumbuhan stek pucuk sowang (Xanthostemon novaguinensis val) terhadap pemberian berbagai konsentrasi hormon IBA (Indole Butyric Acid). Skripsi Sarjana Kehutanan, Universitas Negeri Papua, Manokwari.

Mora, S. 2010. Persentase hidup anakan masoi (Cryptocarya massoy (Okem) Kosterm) dari persemaian ke polybag. Skripsi Sarjana Kehutanan UNIPA, Manokwari.

Pallardy, SG. 2008. Physiology of woody plants (Third Edition). Academic Press.

Rumakewi, LJ. 2012. Pengaruh naungan terhadap pertumbuhan anakan masoi (Cryptocarya massoia (Okem ) Kosterm) di Hutan Pendidikan Anggori. Skripsi Sarjana Kehutanan, Universitas Negeri Papua, Manokwari.

Salisbury FB dan Ross CW. 1995. Fisiologi tumbuhan. Jilid 3; terjemahan Lukman DR dan Sumaryono. ITB Bandung.

Samber, HT. 2002. Pengaruh beberapa tingkat konsentrasi IBA (Indole Butyric Acid) terhadap perakaran stek pucuk semai pohon Lawang (Cinnamomum cullilawan Bl). Skripsi Sarjana Kehutanan, Universitas Negeri Papua, Manokwari.

Santoso,U dan Nursandi,F. 2001. Kultur jaringan tanaman. UMM Press, Malang.

Siddiqui MI, Hussain SA. 2007. Effect of Indole Butyric Acid and types of cuttings on root initiation of Ficus hawaii. Sarhad J.Agric. Vol.23 No.4.

Sikoway, I. 2009. Pengaruh perendaman dan pemanasan secara sangai terhadap perkecambahan benih Masoi (Cinnaamomum massoia Schewc. atau Cryptocarya masoy (Okem) Kosterm). Skripsi Sarjana Kehutanan Jurusan Budidaya, UNIPA. Manokwari.

Triantoro, RGN, Susanti, CME. 2007. kandungan bahan aktif kayu Kulilawang (Cinnamomum culilawan B1.) dan Masoi (Cryptocaria massoia). J.Ilmu \& Teknologi Kayu Tropis Vol.5 No.2.

Yang FO, Wang J, Li Y. 2015. Effects of cutting size and exogenous hormone treatment on rooting of shoot cuttings in Norway spruce. New Forest 46:91-105. 